\title{
RESILIÊNCIA SOCIOAMBIENTAL-ESPACIAL URBANA À INUNDAÇÕES: POSSIBILIDADES E LIMITES NO BAIRRO CAJURU EM CURITIBA (PR)
}

\author{
SOCIOENVIRONMENTAL-SPATIAL URBAN RESILIENCE TO \\ FLOODING: POSSIBILITIES AND LIMITS ON \\ CAJURU DISTRICT (CURITIBA-BRÉSIL)
RESILIENCIA SOCIOAMBIENTAL-ESPACIAL URBANA A LAS
INUNDACIONES: POSIBILIDADES Y LÍMITES EM EL
BARRIO CAJURU CURITIBA (BRASIL))

\section{Francisco Mendonça}

Pós-doutorado em Geografia. Docente no Programa de Pós Graduação em Geografia da UFPR. Departamento de Geografia. Universidade Federal do Paraná.

Av. Cel. Francisco H dos Santos, 100 - Centro Politécnico, Edifício João José Bigarella - Sala $108-1^{\circ}$ andar, CEP: 81531-980 - Caixa Postal 19001, Curitiba - Paraná.

e.mail: chico@ufpr.br

\section{Elaiz Aparecida Mensch Buffon}

Doutoranda em Geografia pela Universidade Federal do Paraná. Bolsista CAPES.

Av. Cel. Francisco H dos Santos, 100 - Centro Politécnico, Edifício João José Bigarella - Sala $108-1^{\circ}$ andar, CEP: 81531-980 - Caixa Postal 19001, Curitiba - Paraná.

e.mail:eambuffon@gmail.com

\section{Francisco Jablinski Castelhano}

Mestrando em Geografia pela Universidade Federal do Paraná.

Av. Cel. Francisco H dos Santos, 100 - Centro Politécnico, Edifício João José Bigarella - Sala $108-1^{\circ}$ andar, CEP: 81531-980 - Caixa Postal 19001, Curitiba - Paraná.

e.mail: castelhano@gmail.com

\section{Gina Sitoe}

Doutorando em Geografia pela Universidade Federal do Paraná. Av. Cel. Francisco H dos Santos, 100 - Centro Politécnico, Edifício João José Bigarella - Sala 108 - $1^{\circ}$ andar, CEP: 81531-980 - Caixa Postal 19001, Curitiba - Paraná.

PPGEO - UFPR

e.mail:gaasitoe@yahoo.com.br 


\section{Resumo}

Os problemas socioambientais urbanos na atualidade são diversos e apresentam uma complexidade existentes na análise das medidas que visam diminuir os impactos a tais problemas associados. Essa complexidade se apresenta na ciência e nas políticas públicas pelo uso de novos conceitos, que nem sempre permitem a sua aplicação em determinados contextos de riscos e vulnerabilidades socioambientais urbanos. O conceito de resiliência espacial surge nestas dimensões como sendo a capacidade de um ambiente, ou de uma sociedade, regressar a sua situação prévia a qualquer impacto sofrido. Nesse sentido, a presente análise visa caracterizar as dimensões das (não) possibilidades de aplicações da resiliência espacial urbana frente à problemática socioambiental atrelada às inundações no bairro Cajuru em Curitiba (PR). O estudo demonstra que lugares constantemente impactados por eventos de inundações encontram-se inseridos em áreas de média a alta vulnerabilidade social, ou mesmo em baixa vulnerabilidade social, mas que caracterizam um processo de favelização em micro-localidade dentro de um setor censitário. Com isso, questiona-se a capacidade de resiliência espacial nesses lugares deve realmente ser aplicada como uma medida frente à problemática socioambiental das inundações ali verificadas.

Palavras-chave: Resiliência Espacial Urbana; Vulnerabilidades; Inundações; Bairro Cajuru.

\section{Abstract}

Urban environmental problems are diverse and have an existing complexity in the analysis of measures to reduce the impacts associated with such problems. This complexity presents in science and public policy for the use of new concepts, which do not always allow their application to certain risks and urban contexts social and environmental vulnerabilities. The spatial concept of resilience arises in these dimensions as the ability of an environment, or a society, return to their previous situation any sustained impact. In this sense, this analysis aims to characterize the dimensions of (not) possible applications of spatial urban resilience against the social and environmental problems linked to flooding in the Cajuru District in Curitiba (PRBrazil). The study demonstrates that places constantly impacted by flooding events are inserted into the middle areas highly vulnerable, or even lower social vulnerability but featuring a favelization process in micro-location within a census tract. It asks the spatial resilience in these places really should be applied as a front as the environmental problem of flooding there checked.

Key-words: Urban Spatial Resilience; Vulnerabilities; Floods; Cajuru District. 


\section{Resumen}

Los problemas socioambientales urbanos actuales son diversos y tienen una complejidad bajo el análisis de las medidas para reducir los impactos asociados a este tipo de problemas. Esta complejidad se presenta en la ciencia y la política pública para el uso de nuevos conceptos, que no siempre permiten su aplicación a ciertos riesgos y contextos urbanos sociales y vulnerabilidades ambientales. El concepto espacial de la resiliencia surge en estas dimensiones como la capacidad de un entorno, o de una sociedad, el retorno a la situación anterior después uno impacto sostenido. En este sentido, este análisis tiene como objetivo caracterizar las dimensiones de las (no) posibles aplicaciones de la resiliencia urbana socioambiental-espacial en face a los problemas sociales y ambientales vinculados a las inundaciones en el barrio Cajuru en Curitiba (PR). El estudio demuestra que los lugares constantemente afectados por eventos de inundación se insertan en las zonas de medias a alta vulnerabilidad, incluso más bajo de vulnerabilidad social, pero que registran un proceso de favelización en micro-ubicación dentro de una sección censal. Se pregunta si la resiliencia espacial en estos lugares realmente debe ser aplicada como un frente al problema ambiental de la inundación registrada?

Palabras-claves: Resiliencia espacial urbana; Vulnerabilidad, Inundaciones; Barrio Cajuru. 


\section{INTRODUÇÃO}

A problemática socioambiental urbana brasileira está amplamente envolvida, de múltiplas maneiras, com a gênese e o enfrentamento dos impactos derivados do processo de urbanização no país, explicitamente caracterizado pelo que Santos (1993) concebe com “urbanização corporativa”. Os reflexos desse processo configuram um cenário de tensões tanto da ordem política e econômica quanto social, que se repercutem de maneira direta uma conjunção de fatores e ações degradantes da qualidade e das condições de vida urbana.

Essas ações caracterizam a (re)produção do espaço urbano brasileiro, fortemente marcado por aglomerações urbanas nas quais sobressaem profundas desigualdades sociais e econômicas associadas, portanto, a uma sociedade fragmentada e hierarquizada. Nestes contextos verifica-se uma expressiva segregação espacial caracterizada por extensos bolsões intraurbano destituídos de serviços e de infraestrutura adequados, que se configuram como potencializadores de riscos e vulnerabilidades socioambientais em face dos eventos de inundações.

As inundações urbanas e o corolário de problemas a elas associados não configuram novidades quando se analise os problemas socioambientais atinentes às cidades brasileiras, ainda que a perspectiva midiática acerca de tais situações insista na concepção de que elas são recentes e que tendem a intensificar-se. É importante citar que as inundações urbanas são fenômenos naturais atrelados à eventos extremos de chuva e que promovem impactos socioambientais de grande monta nas sociedades, especialmente, naquelas inseridas em áreas urbanas. Mas, o caráter natural das inundações é amplamente modificado pelos impactos da urbanização, de modo a majorar sua magnitude e frequência de ocorrência (CARNEIRO e MIGUEZ, 2011).

Assim, compreende-se que os riscos socioambientais associados aos eventos de inundações em área urbana são ampliados em decorrência do maior número de população exposta, da tipologia construtiva (ocupação densa) e da grande gama de atividades econômicas ali existentes. Neste sentido Mendonça (2015, p.47), ao refletir sobre a associação entre a expansão urbana acelerada - desordenada e a formação de situações de risco socioambiental nas cidades, observa que

"mesmo em condições habituais de pluviosidade pouco intensa os impactos são cada vez mais representativos; ou seja, mesmo desconsiderando-se a questão das mudanças climáticas, um evento climático corriqueiro pode, na atualidade, desencadear a formação de riscos importantes devido, sobretudo, à urbanização em áreas de risco e não necessariamente à excepcionalidades atmosféricas." 
Assim, compreende-se que os impactos decorrentes das inundações urbanas estão fortemente associados com as condições de exclusão e inclusão da população aos benefícios da cidade, bem como, das medidas de adaptação e mitigação frente aos impactos desse fenômeno. Mendonça et al (2015) confirmam essa assertiva ao analisarem as medidas de adaptação às inundações urbanas na cidade de Pinhais-PR; concluem eles que a capacidade de adaptação da população está diretamente relacionada às suas condições socioeconômicas e às atuações do poder público, que também atua seletivamente.

Para Mendonça (2011) as diferentes condições sociais, econômicas, culturais e políticas da população geram distintas situações de vulnerabilidade da social aos riscos socioambientais, que emergem a formação de regiões de risco (regions of risk) e regiões em riscos (regions at risk) conforme Hogan e Marandola (2004). Portanto, "a vulnerabilidade socioambiental urbana evidencia a heterogeneidade dos impactos advindos dos riscos que se abatem sobre uma dada população” (MENDONÇA, 2011, p.114).

Pelling (2003) considera três termos chaves na sua compreensão da vulnerabilidade, a saber: exposição (exposure), resistência (resistenace) e resiliência (resilience). A exposição é um produto da localização física associada à condição de moradia e pressões naturais dos lugares, e a resistência corresponde aos reflexos da economia e da saúde, de modo a indicar a capacidade e um indivíduo ou grupo de suportar os impactos dos riscos. Por fim considera que a resiliência é a capacidade de um ator para lidar ou adaptar-se aos perigos (PELLING, 2003).

Mendonça (2011) também considera que a resiliência está relacionada à adaptação e que ela consiste em variações individuais e/ou coletivas em resposta aos fatores de risco, sendo que se refere, em geral, à capacidade de um ambiente, ou sociedade, de voltar às condições anteriores após ser impactada/ vitimada por um evento de caráter extremo (natural ou social/tecnológico).

Entretanto, os conceitos de risco, vulnerabilidades, adaptação e resiliência se tornam mais complexos quando aplicados no contexto de países não desenvolvidos. As grandes cidades destes países são marcadas por assentamentos humanos nos quais um conjunto complexo de problemas dificulta a compreensão de riscos isolados, posto que não se pode mais compreendê-los segundo uma ordem pré-estabelecida (natural, social ou tecnológica), de tal modo que são riscos híbridos, sendo que um risco intensifica a ocorrência do outro (MENDONÇA, 2015).

A Região Metropolitana de Curitiba, especialmente a cidade polo (Curitiba), constitui um excelente exemplo desse tipo de cenário - urbanização corporativa - no qual se ex- 
plicitam problemas socioambientais de grande monta, como aqueles associados às inundações urbanas; seu acelerado crescimento nas três ultimas décadas (3.223.836 habitantes em 2010) atestam a intensificação dos problemas socioambientais. Embora, a cidade de Curitiba tenha vários títulos-slogans que a ressaltam como positividade urbana, tais como “exemplo de planejamento urbano" (1970), “capital de primeiro mundo" (1980/1990), “capital ecológica" (1990) e "capital social" (2000) (MENDONÇA, 2004a), a realidade evidencia "de forma flagrante, condições de expressiva vulnerabilidade socioambiental" (MENDONÇA, 2004b, p.148) de forma mais expressiva nas populações expostas a condição de pobreza e miserabilidade (BUFFON, 2016).

Para além dessa condição de vulnerabilidade social tomam destaque os eventos hidrometeorológicos extremos ou excepcionais que derivam de desvios positivos e negativos em relação à média da pluviosidade para Curitiba (ZANELLA, 2006). As inundações urbanas merecem destaque em razão dos impactos decorrentes do rápido e desordenado processo de urbanização da cidade, que ocupou e configurou novas áreas de riscos (MENDONÇA et al, 2013). As inundações urbanas fazem parte da história da evolução da cidade, cuja lógica se processou ao longo dos principais rios e planícies de inundações, refletindo, assim na formação de áreas de risco a inundações.

O bairro Cajuru (Figura 1) é o terceiro mais populoso da cidade e aquele no qual se registrou um acelerado incremento demográfico nas duas últimas décadas; sua população total saltou de 15.982 habitantes em 1970 para 96.200 habitantes no ano de 2010, boa parte em condições de pobreza e miséria. O bairro se localiza na porção leste da cidade, promovendo conurbação com a cidade de Pinhais e São José dos Pinhais (Figura 1), o que efetiva o desafio de uma gestão de riscos que ultrapasse a escala intraurbano e considere a escala intrametropolitano. 
Figura 1: Brasil - Estado do Paraná - Região Metropolitana de Curitiba (RMC) - Município de Curitiba - Bairro Cajuru (PR): Localização geográfica e caracterização da densidade demográfica.
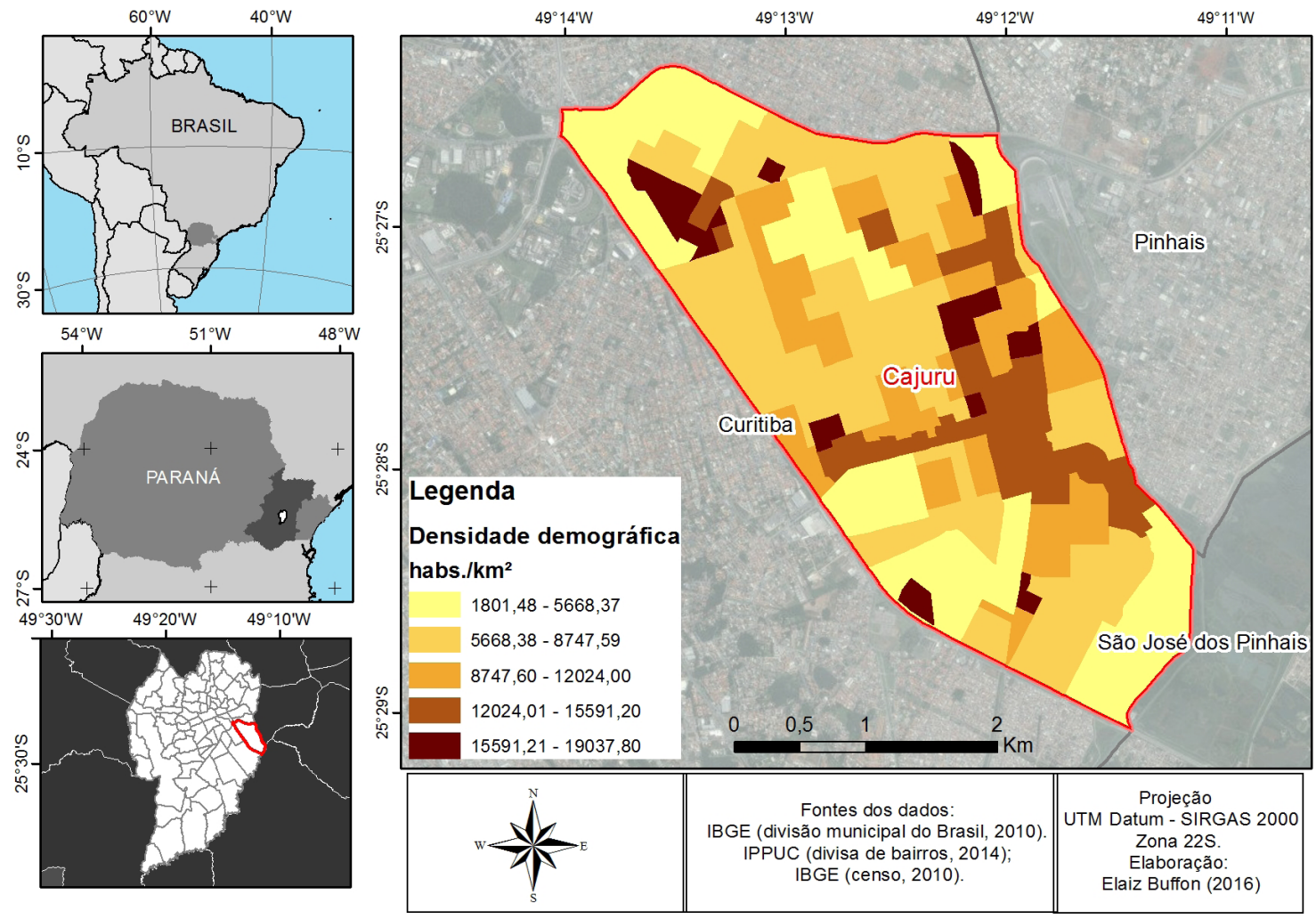

Nesta perspectiva, Oliveira e Herrmann (2006, p. 190) salientam que "as cidades constituem hoje o maior exemplo de degradação ambiental, colocando em risco a segurança e a qualidade de vida de sua população, constituindo um palco de embates ecológicos". O bairro Cajuru em Curitiba explicita esse tipo de cenário, haja visto que se caracteriza por apresentar o maior número de registros de impactos associados às inundações urbanas na Região metropolita de Curitiba (SUDERHSA, 2002; ZANELLA, 2006).

Nesse contexto, a problemática socioambiental urbana relativa às inundações pode ser enfocada por diversos prismas, vide a complexidade de tais questões e sua abrangência. Este texto coloca em evidencia uma abordagem geográfica da referida problemática na perspectiva de exercitar a aplicação do conceito de resiliência espacial urbana, e toma como estudo de caso as inundações no bairro Cajuru em Curitiba. Discussões anteriores realizadas por Mendonça (2015) trazem o seguinte questionamento, norteador desta pesquisa: Que condicionantes e limitantes se colocam sobre a aplicação da resiliência em espaços urbanos impactados por eventos extremos do clima? 


\section{ABORDAGEM GEOGRÁFICA DA VULNERABILIDADE E RESILIÊNCIA}

A particularidade do estudo de caso do bairro Cajuru, em Curitiba / Brasil, nada mais é que uma manifestação local de um problema com ocorrência generalizada em grande parte das cidades do Brasil. Assim, a perspectiva hipotético-dedutiva (MARCONI e LAKATOS, 2011) associada ao Sistema Ambiental Urbano (MENDONÇA, 2004) constitui a escolha metodológica na qual o estudo foi desenvolvido.

A identificação das áreas críticas a inundações, considerando o perímetro do bairro Cajuru, pautou-se no levantamento de dados do Plano Diretor de Drenagem para a Bacia do Rio Iguaçu na Região Metropolitana de Curitiba elaborado pela Superintendência de Desenvolvimento de Recursos Hídricos e Saneamento Ambiental do Paraná. Este documento foi disponibilizado pelo Instituto das Águas do Paraná no ano de 2002, sendo que as áreas críticas a inundações foram intituladas como manchas de inundação considerando o tempo de recorrência de 10 e 25 anos.

No que se refere aos casos de inundações e alagamentos, registrados durante o período de 2007 a 2015, realizou-se uma coleta de dados junto à Defesa Civil de Curitiba e ao Instituto de Pesquisa e Planejamento Urbano de Curitiba (IPPUC). Esses dados referem-se aos registros por dia, mês, ano e endereçamento dos locais afetados por inundações.

Ainda, para a identificação de áreas sujeitas a inundações, realizou-se um levantamento de notícias em jornais impressos e websites sobre a ocorrência de tais eventos no bairro Cajuru em Curitiba. Dentre os materiais identificados, selecionou-se para utilização nesta pesquisa, dados do Jornal do Estado do ano de 1999 disponibilizado pela Biblioteca Pública do Paraná, e também dados disponibilizados através de um documento filmográfico de produzido por Marinho (2014)

Uma vez elaborado o mapas-base (figura 2) e identificados os pontos de maior ocorrência de inundações e da caracterização da vulnerabilidade social, procedeu-se ao levantamento de campo para a checagem de tais informações; nestas atividades foram também verificadas as intervenções urbanas visando a redução dos impactos, a adaptação e a resiliência às mesmas. Fotografias destas localidades e seu georreferenciamento sobre um mapa-síntese (Figura 3) completam a elaboração técnica do estudo que, ao cotejar com a literatura específica e as bases teóricas, possibilitaram a elaboração da análise aqui apresentada.

\section{Mapeamento da vulnerabilidade social}

O mapeamento da vulnerabilidade social do bairro Cajuru foi realizado com base na técnica de cartografia de síntese (MARTINELLI 1991, 2003; SAMPAIO, 2012), por meio da 
álgebra de mapas e análise multicritério, conforme aplicado por Buffon (2016). Num primeiro momento procedeu-se à eleição das variáveis a serem adotadas no mapeamento da vulnerabilidade social. Essa eleição baseou-se nos dados disponíveis em escala temporal e espacial iguais comtemplando elementos que interferem na condição de vida da população.

Após isso realizou-se o processo de normalização e padronização dos dados (SAMPAIO, 2012) por setores censitários do bairro de modo a constituir, também, a síntese elementar do mapeamento final da vulnerabilidade social. Com isso realizou-se a ponderação das categorias e variáveis, de modo a atribuir pesos para cada uma, com a soma dos pesos igual a 100\% (Quadro 1). Optou-se por utilizar peso igual para todas as variáveis, a fim de apresentar uma situação geral das condições sociais, ou seja, atribuiu-se a mesma importância para todas as variáveis, uma vez que todas interferem na condição de vida da população, e desse modo, na condição de vulnerabilidade social, que demonstra efetivação de áreas de precárias condições de vida (pobreza).

\section{Quadro 1: Bairro Cajuru - Curitiba/PR: Pesos de categorias e sub-categorias no mapeamento de vulnerabilidade social.}

\section{\begin{tabular}{l|l|l|l|l} 
Categoria & Peso & Sub-Categoria & Peso & Variáveis
\end{tabular}}

\begin{tabular}{|c|c|c|c|c|}
\hline & & Alfabetização & $14,285 \%$ & $\begin{array}{l}\text { Total de responsáveis não } \\
\text { alfabetizados }\end{array}$ \\
\hline & & Renda & $14,285 \%$ & $\begin{array}{l}\text { Total responsável com renda até } 2 \\
\text { salários mínimos }\end{array}$ \\
\hline & & $\begin{array}{l}\text { Lixo em } \\
\text { logradouro }\end{array}$ & $14,285 \%$ & $\begin{array}{l}\text { Domicílios particulares permanentes } \\
\text { com lixo acumulado nos } \\
\text { logradouros }\end{array}$ \\
\hline $\begin{array}{c}\text { Características } \\
\text { dos domicílios } \\
\text { e dos }\end{array}$ & $100 \%$ & $\begin{array}{l}\text { Ocupação } \\
\text { irregular }\end{array}$ & $14,285 \%$ & $\begin{array}{l}\text { Domicílios particulares permanentes } \\
\text { em outra condição de ocupação } \\
\text { (não são próprios, alugados, nem } \\
\text { cedidos) }\end{array}$ \\
\hline moradores & & $\begin{array}{l}\text { Rede de esgoto ou } \\
\text { fossa séptica }\end{array}$ & $14,285 \%$ & $\begin{array}{l}\text { Domicílios particulares permanentes } \\
\text { sem rede de esgoto ou fossa séptica }\end{array}$ \\
\hline & & Coleta de lixo & $14,285 \%$ & $\begin{array}{l}\text { Domicílios particulares permanentes } \\
\text { sem coleta de lixo, com depósito } \\
\text { na propriedade, terreno baldio, } \\
\text { logradouro, rio, lago ou mar }\end{array}$ \\
\hline & & $\begin{array}{l}\text { Abastecimento de } \\
\text { água }\end{array}$ & $14,285 \%$ & $\begin{array}{l}\text { Domicílios particulares permanentes } \\
\text { com fonte de água proveniente de } \\
\text { poço, rios, açudes ou água da chuva }\end{array}$ \\
\hline
\end{tabular}


Os dados e os materiais utilizados para o mapeamento correspondem, respectivamente: a base de informações do Censo Demográfico 2010, resultados por setor censitário; e os dados vetoriais por setor censitário e por bairro. Todos esses dados e materiais são disponibilizados pelo Instituto Brasileiro de Geografia e Estatística (IBGE), com exceção do arquivo vetorial de limite do bairro que foi coletado junto ao Instituto de Pesquisa e Planejamento Urbano de Curitiba (IPPUC).

\section{A resiliência espacial urbana em áreas de inundação}

Para verificar a aplicação do conceito de resiliência espacial urbana na analise das áreas com processo histórico-atual de eventos de inundações realizou-se um trabalho de campo no dia 13 de agosto de 2015. As áreas de visita e de observação in loco foram previamente definidas com base na mancha de inundações no bairro (áreas de risco) e segundo a identificação dos lugares (dados da Defesa Civil e de reportagens jornalísticas) que registraram inundações e/ou alagamentos nos últimos anos.

Assim, a realização do levantamento de trabalho de campo visou verificar a possibilidade da aplicação da resiliência espacial urbana nas áreas impactadas por inundações; tratou-se de verificar a dimensão espacial-ambiental-geográfica da resiliência, e não a resiliência biológica, material, social ou econômica, as mais comuns na literatura acerca do tema da resiliência (MENDONÇA, 2015). Para tanto considerou-se que a resiliência espacial urbana pode ser bem-sucedida ou questionável, haja visto as diferentes condições socioambientais dos lugares (risco e vulnerabilidade), tendo sido registrada por meio de imagens (fotos) que ilustram este texto.

\section{VULNERABILIDADE SOCIAL E ÀS INUNDAÇÕES NO BAIRRO CAJURU EM CURITIBA (PR)}

A expansão e densificação urbana como produtoras de novas dinâmicas socioambientais em Curitiba tornaram-se mais evidentes nas três últimas décadas, momento em que a urbanização foi marcada por uma nova fase econômico-política (pós 1970) na qual a industrialização tomou grande impulso, estendendo-se até o presente; a indústria automobilista constitui um dos principais ramos a dinamizar a econômica local neste período (FIRKOWSKI, 2001). Conforme será demonstrado nos resultados, a efetivação dessa expansão no bairro Cajuru, repercutindo-se numa produção do espaço urbano com características de segregação socioespacial, portanto áreas com índices de vulnerabilidade e qualidade de vida distantes entre si, e graves problemas socioambientais, tais como falta de saneamento básico, moradias insalobras e altamente vulneráveis entre outras. 
No contexto da industrialização recente, tanto da Região Metropolitana de Curitiba como do estado do Paraná, a urbanização foi fortemente acelerada, porém destituída de políticas públicas norteadoras da expansão urbana. Na RMC e na cidade de Curitiba ocorreu um significativo salto quantitativo da população urbana, que pode ser observado no incremento da população do bairro Cajuru, por exemplo, que passou de um numero aproximado de 16.000 habitantes na década de 1970 para proximo de 100.000 habitantes na última década (Gráfico 1).

\section{Gráfico 1: Crescimento populacional do bairro Cajuru em Curitiba (PR).}

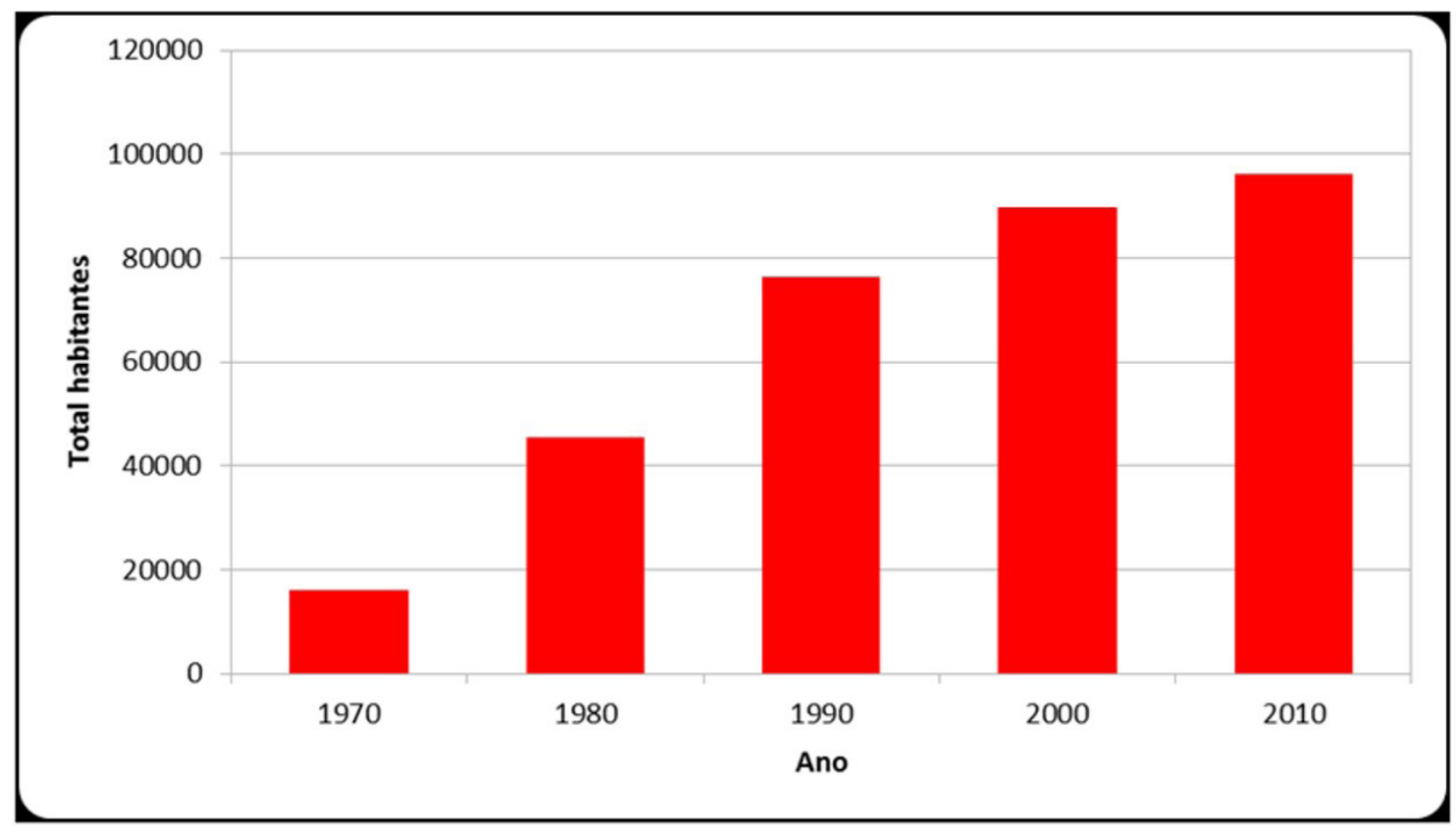

Fonte: IBGE, 2010. Elaboração: Autores (2015).

Mesmo que preocupações referentes ao uso e ocupação do solo na cidade de Curitiba tenham ganhado relevância neste mesmo período de crescimento populacional do bairro (MENDONÇA, 2004a e 2004c), a expansão urbana não atendeu as diretrizes constantes do planejamento oficial. Grande parte da população e da indústria concentrou-se na porção leste da cidade e RMC, contrariando ao recomendado desde final dos anos setenta em vários planos de desenvolvimento urbano-regional, configurando na atualidade na formação de áreas de riscos de toda ordem quando, outrora, compunham áreas de proteção ambiental (FIRKOWSKI, 2002; MENDONÇA, 2004a; COMEC, 2006).

Conforme Mendonça (2004c) e Mendonça et al. (2013 e 2015), as inundações no bairro Cajuru não são fenômenos recentes (problemas da última década) dado que fazem parte do processo de ocupação do território do bairro. E, embora a literatura apresente que são fenômenos naturais, com intervalo de recorrência que varia de acordo com as carac- 
terísticas climáticas regionais (LEOPOLD et al, 1964; TUCCI, 2003), torna-se relevante compreender as pressões sociais que, especialmente na atualidade, influenciam na magnitude e na frequência da ocorrência desse tipo de risco natural.

Zanella (2006) aponta como principais problemas socioambientais do bairro Cajuru a elevada proporção de ocupações irregulares, principalmente aquelas estabelecidas nas várzeas dos rios e córregos que compõem a sub-bacia do Rio Atuba; a elevada taxa de impermeabilização do solo proporciona aumento do escoamento superficial que, atrelada aos problemas de drenagem urbana, derivam em sucessivos e intensos eventos de inundações. Altas taxas de densidade demográfica associadas a difíceis condições de vida da população - notadamente pobreza e miserabilidade, amplia e intensifica a magnitude dos impactos.

A parte da população mais vulnerável, e, portanto, mais afetada, pelas inundações é aquela mais pobre - carente de infraestrutura básica, processo este não atual - e que tem suas habitações nas áreas de riscos, especialmente, localizadas nas margens de rios e córregos (Figura 2). A ocupação de áreas mais vulneráveis fisicamente às inundações (representada pelas manchas de inundação - Figura 3) por populações mais vulneráveis quanto às condições sociais e econômicas (vulnerabilidade de média a alta e muito alta (Figura 2) resulta na intensificação dos impactos derivados das inundações. Estes graves problemas não devem, por sua vez, ser concebidos como decorrentes apenas das mudanças climáticas globais e/ou ao aquecimento global, mas, sobretudo ao intenso processo de ocupação das áreas de riscos pela sociedade.

Examinando a configuração espacial da vulnerabilidade social do bairro Cajuru (Figura 2) constata-se, facilmente, que a mesma é mais elevada nas porções próximas ou dentro das várzeas dos rios e dos córregos locais. Portanto, grande parte dessas áreas se configuram como palco de riscos híbridos permanentes, ou seja, não obedecem mais a uma única ordem de riscos sociais, naturais e tecnológicos. Para exemplificar, cita-se que em situações de riscos naturais tais como eventos de inundações, os riscos sociais são intensificados e, por sua vez, também intensificam os riscos naturais, ou seja, tornam-se riscos híbridos, as conjunções de diferentes riscos em um único ambiente tornam os impactos muito mais intensos e graves, no tempo e no espaço. 
Figura 2: Bairro Cajuru-Curitiba (PR) - Interface entre a caracterização socioambiental e às áreas de inundações.

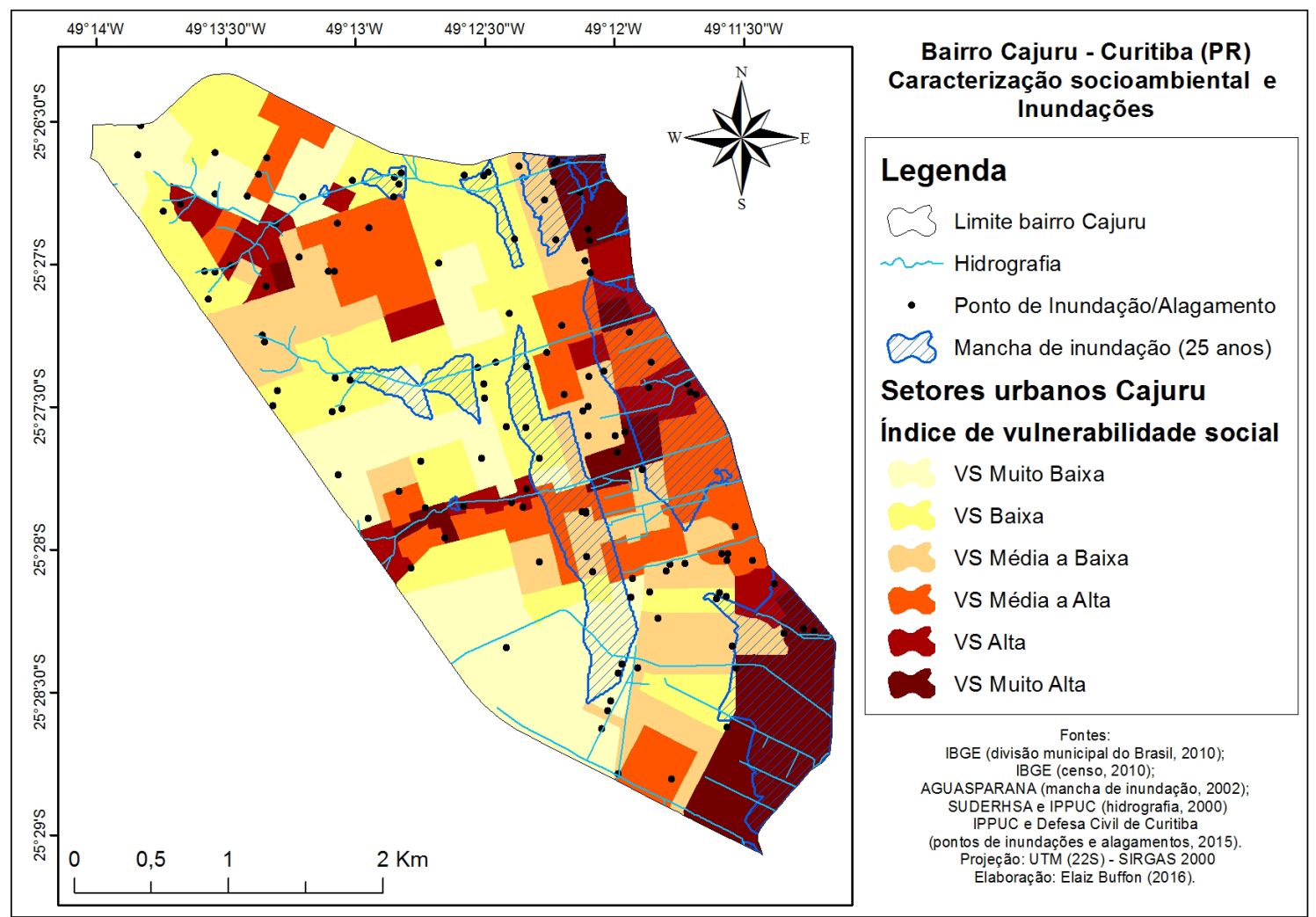

Considerando o cenário de inundações e a vulnerabilidade social no bairro Cajuru, definiram-se pontos críticos de inundações na localidade, visando desenvolver uma análise da resiliência espacial urbana nos mesmos em momentos a priori e a posteriori do evento de inundação. Os pontos analisados evidenciam ausência e/ou da ineficaz rede de drenagem pluvial (Tabela 1a) e ocupação humana de áreas de riscos a inundações localizadas próximas a várzea de rios (Tabela $1 \mathrm{~b}$ ).

A caracterização destas áreas piloto ressalta que os espaços são ocupados sem devido planejamento como orientador da produção da cidade e que, mesmo após os impactos decorrentes de inundações, não foram implementadas medidas de prevenção, adaptação e mitigação com o fim de reduzir a vulnerabilidade socioambiental destes lugares. Intervenções sociais e políticas na gestão dos riscos tornam-se necessidades evidentes e preementes no bairro Cajuru, especialmente nas localidades de risco híbridos, como o demonstra os dados da Tabela 1. 
Tabela 1: Bairro Cajuru-Curitiba (PR) - Caracterização de dois pontos de inundação: Maio Junho / 2014 - Agosto / 2015.

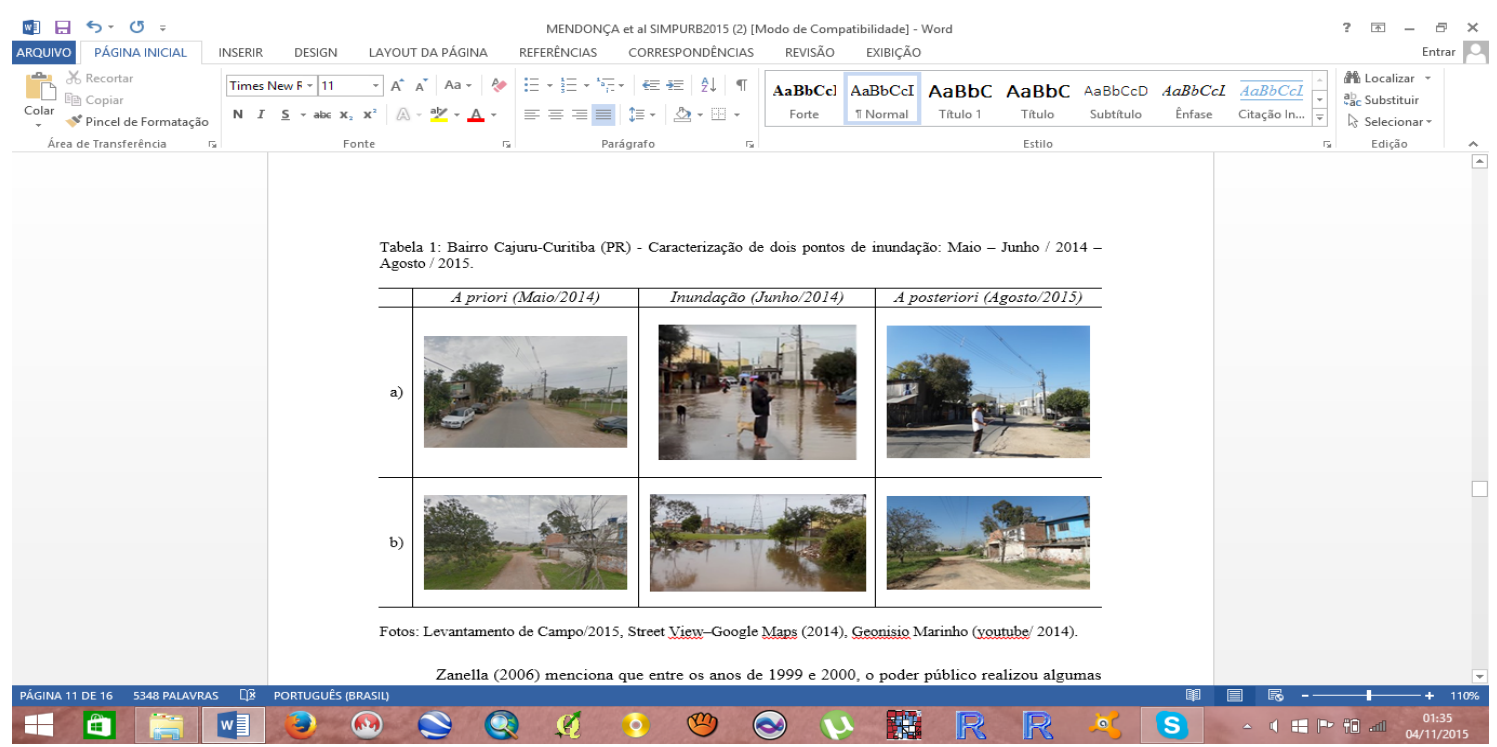

Fotos: Levantamento de Campo/2015, Street View-Google Maps (2014), Marinho (2014).

Zanella (2006) menciona que entre os anos de 1999 e 2000, o poder público realizou algumas medidas para minimizar os impactos das inundações. Dentre essas medidas citam-se o alargamento do canal do Rio Atuba, a criação do Parque Linear do Cajuru, a abertura e pavimentação de ruas, o aumento do diâmetro das tubulações. Tais obras, segundo a autora apresentaram resultados eficazes, entretanto, nota-se no contexto atual (ano de 2015), que essas obras são extremamente seletivas intra-bairro, ou seja, caracterizam-se por serem pontuais e que em sua gênese visam atender as populações mais favorecidas economicamente e que se situam em áreas menos vulneráveis. Há, todavia, um considerável período de tempo entre aquelas intervenções e o momento atual no qual pouco se implementou quanto à redução dos impactos das inundações.

\section{RESILIÊNCIA ESPACIAL EM FACE À INUNDAÇÕES: APLICAÇÃO NO BAIRRO CAJURU EM CURITIBA (PR)}

Compreendendo a resiliência espacial urbana como a capacidade de resistência do ambiente e da população frente a um determinado impacto, ou seja, a capacidade de retornar às condições de pré-desastre após um dado desastre natural (MENDONÇA, 2015), questiona-se: Como aplicar a resiliência espacial em determinadas localidades urbanas de elevado risco e vulnerabilidade socioambiental atrelado às inundações no contexto de países não desenvolvidos, como é o caso do bairro Cajuru em Curitiba (PR)?

Para exercitar a aplicação da concepção de resiliência espacial às inundações na localidade em analise foram escolhidas algumas áreas (Figura 3) nas quais a relação entre 
risco, vulnerabilidade e ocupação humana explicita intensa problemática socioambiental. Durante a aplicação do exercício ficou evidente que a resiliência espacial encontra importantes limitações devido à condição socioeconômica e espacial da área no momento pré-evento de inundação. Em muitas situações a questão mais evidente diz respeito ao que é mesmo o desastre ou o risco, ou seja, a condição de favelamento de uma população-área é menos ou mais grave que o fenômeno da inundação? Considerando este questionamento a saída encontrada para o desfecho do trabalho foi a de classificar as áreas conforme a aplicação da resiliência com sucesso e com aplicação questionável, como se verá a seguir.

A quase totalidade dos lugares indicados em condição de resiliência espacial questionável frente às inundações (Figura 3) situa-se em contextos de média a alta e muito alta vulnerabilidade social (Tabela 2 - b, c, e, f, g). Outras áreas também consideradas dentro desta condição, porém localizadas em setores censitários de baixa vulnerabilidade social são representadas por micro-localidades, como algumas ruas e/ou ocupações subnormais ao longo de cursos hídricos (Tabela $2-\mathrm{d}$ ).

As áreas consideradas como apresentando condição de resiliência espacial bem-sucedida foram identificados quando medidas de adaptação, controle e mitigação das inundações são efetivadas no ambiente (Tabela 2 - a). Em algumas delas não houve o retorno do local (espaço) às condições anteriores ao desastre natural, mas sim a remoção completa de populações que as ocupavam posto que se encontravam altamente expostas ao risco.

\section{Figura 3: Contextos sociais dos lugares de análise da aplicação da resiliência espacial urbana} frente às inundações no bairro Cajuru em Curitiba (PR).

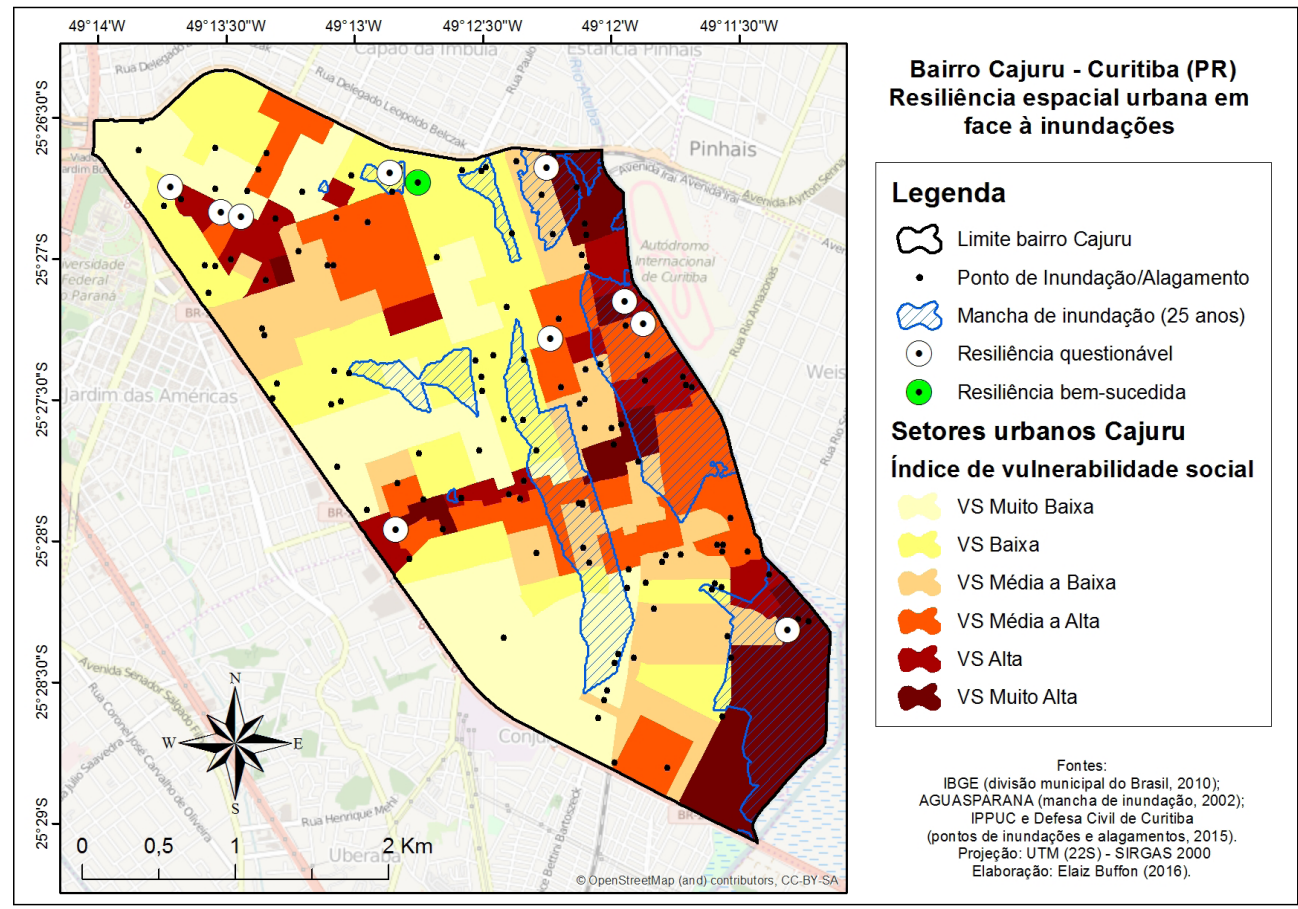


Tabela 2: Aplicação de resiliência espacial urbana associada às inundações.

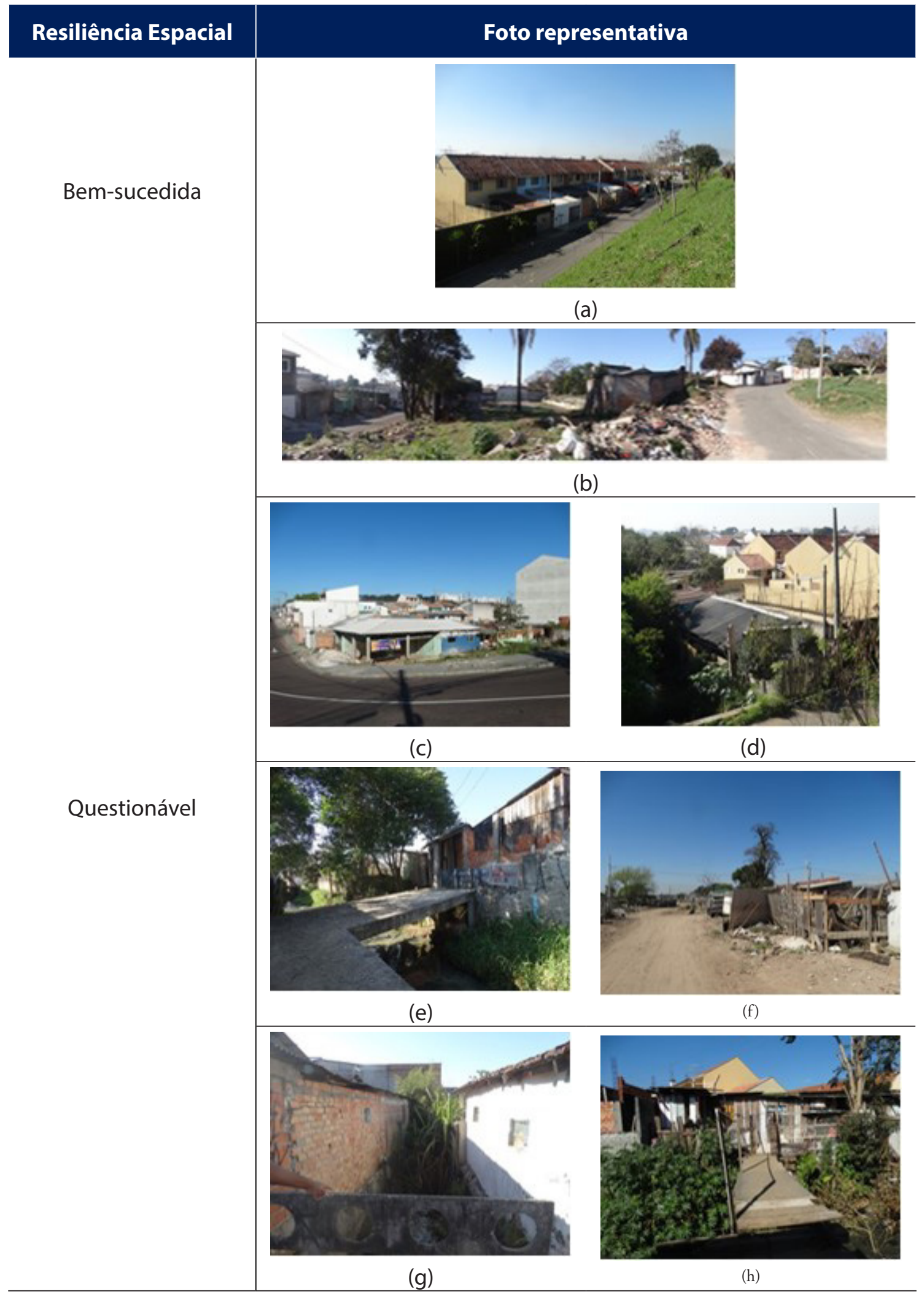

Fotos: Levantamento de Campo (2015). Elaboração: Autores (2015).

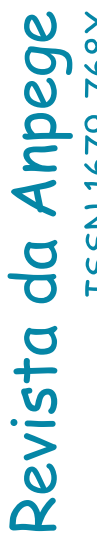

\section{a}

a 
O conceito de resiliência espacial pode ser aplicado em grande parte das áreas atingidas por eventos de inundação conforme foi verificado no bairro Cajuru (Figura 3 e Tabela 2). Entretanto, essas áreas continuam cotidianamente expostas a situações de risco posto que são fortemente marcadas por precárias condições de vida (vulnerabilidade socioambiental) da sociedade que nelas vive. Esta constatação corrobora a afirmação de Mendonça (2015, p. 57) quando aponta que "a noção de resiliência como vimos acima se aplica, mas não significa de maneira alguma a garantia de melhores condições de vida para o enfrentamento aos impactos e dar prosseguimento da vida com dignidade".

E nesse sentido, que o presente estudo aponta como questionável a aplicação de resiliência em grande parte das áreas afetadas por inundações no bairro Cajuru em Curitiba. Aplicar a resiliência em tais contextos não significa apenas implementar medidas de adaptação, controle e mitigação em relação às inundações. Tal aplicação implica em aceitar que a condição cotidiana de riscos (vulnerabilidade ambiental) e de elevada injustiça social (vulnerabilidade social), portanto de alta vulnerabilidade socioambiental, não permite que a resiliência seja aplicada em todos os lugares submetidos a impactos de eventos de inundações; em boa parte das vezes a resiliência espacial implica na remoção total de populações de áreas de elevado risco socioambiental.

\section{CONSIDERAÇÕES FINAIS}

As preocupações com a aplicação da resiliência ganharam importância e destaque no contexto das mudanças ambientais e climáticas globais das três últimas décadas. Aplicada às situações de risco a eventos naturais extremos do clima, como as inundações urbanas, a resiliência e sua aplicação demanda aprofundamento conceitual e detalhada análise geográfica espacial, posto que certamente não pode ser aplicada de forma ampla e geral.

Vários elementos apresentados ao longo deste texto levantam ressalvas que devem ser consideradas quanto à aplicação da resiliência espacial, especialmente quando se trata da resiliência espacial urbana. Conclui-se, portanto, que este conceito, muitas vezes confundido com os conceitos de resistência e de adaptação, desafia estudiosos e gestores a questionar a capacidade de um dado sítio de regressar a seu estado anterior após sofrer de um dado impacto ambiental. Tal assertiva se deve ao fato de que as condições socioambientais dos assentamentos humanos dominados por pobreza e miséria (de alta vulnerabilidade social) estão, em boa parte das vezes, associadas a sítios de explicita suscetibilidade a riscos naturais (vulnerabilidade ambiental), o que implica na impossibilidade de se aplicar a resiliência sobre os mesmos. 
A capacidade de resiliência espacial urbana não se consiste sempre em uma medida eficaz perante ao enfrentamento dos impactos decorrentes de inundações, isso porque, muitas das áreas afetadas por inundações em contextos de países não desenvolvidos, tal como verificado no bairro Cajuru em Curitiba, correspondem a espaços marcados por alta vulnerabilidade socioambiental. Nessa lógica, voltar ao estado de pré-desastre natural significa regressar à condição de alta vulnerabilidade aos impactos das inundações.

A problemática das inundações no bairro Cajuru em Curitiba não deve ser pensada a partir da noção de resiliência espacial conforme enfocada nos discursos das mudanças ambientais e climáticas globais; o problema toma maior vulto devido às complicações de ordem social e não diretamente derivado de uma manifestação natural. Nesta perspectiva aponta-se a importância de medidas de mitigação que consistam, num primeiro momento, na elaboração e implementação de um planejamento a longo prazo envolvendo medidas de adaptação, prevenção e controle eficaz das inundações. Ademais, deve se refletir sobre meios de renaturalização dos ambientes de proteção ambiental, que no momento atual configuram-se como áreas de riscos. Acima de tudo faz-se mister promover a justiça social e a equidade social como ações fundamentais ao equacionamento dos problemas socioambientais urbanos, sem as quais a resiliência espacial urbana não logrará sucesso algum.

\section{REFERÊNCIAS}

1. BUFFON, Elaiz A. M. A leptospirose humana no AU-RMC (Aglomerado Urbano da Região Metropolitana de Curitiba/PR) - risco e vulnerabilidade socioambiental. Dissertação (Mestrado em Geografia) - Setor de Ciências da Terra, Programa de Pós-Graduação Geografia, Universidade Federal do Paraná, Curitiba, 2016, 171f.

2. CARNEIRO, Paulo. R. F.; MIGUEZ, Marcelo. G. Controle de inundações em bacias hidrográficas metropolitanas. São Paulo: Annablume, 2011.

3. COMEC - Coordenação da Região Metropolitana de Curitiba. Plano de desenvolvimento integrado da Região Metropolitana de Curitiba: propostas de ordenamento territorial e novo arranjo institucional / Coordenação da Região Metropolitana de Curitiba. Curitiba, 2006, 303p.

4. FIRKOWSKI, Olga L. C. de F. A nova territorialidade da indústria e o aglomerado metropolitano de Curitiba. 278 f. Tese (Doutorado em Geografia Humana) - Faculdade de Filosofia, Línguas e Ciências Humanas, Universidade de São Paulo, São Paulo, 2001.

5. __ A nova lógica de localização industrial no aglomerado metropolitano de Curitiba. Revista Paranaense de Desenvolvimento, Curitiba, IPARDES, n. 103, pgs. 79-100, 2002.

6. HOGAN, Daniel J. e MARANDOLA JR, Eduardo. Natural hazards: os estudos geográficos dos riscos e perigos. Ambiente e Sociedade, vol. 7, n. 2, pgs. 95-109, dez/2004. 
7. IBGE, Censo Demográfico 2010. Disponível em: <http://www.censo2010.ibge.gov.br $>$. Acesso em: 24 set. 2015.

8. LEOPOLD, Luna. B.; WOLMAN, Gordon M.; MILLER, John. P. Fluvial processes in geomorphology. San Francisco: Freeman and Co., 1964.

9. MARCONI, Marina A. e LAKATOS, Eva M. Metodologia do trabalho científico. São. Paulo: Atlas, 2011.

10. MARINHO, Geonisio, ENCHENTE VILA AUTÓDROMO 0706 2014, Disponivel em: < https://www.youtube.com/watch?v=_GSuD9mbJq4>. Acesso em: 20 set. 2015.

11. MARTINELLI, Marcelo. Curso de cartografia temática. 1. ed. São Paulo: Contexto, 1991.

12. Mapas da geografia e cartografia temática. São Paulo: Contexto, 2003.

13. MENDONÇA, Francisco. Abordagem interdisciplinar da problemática ambiental urbanometropolitana: esboço metodológico da experiência do Doutorado em MA\&D da UFPR sobre a RMC - Região Metropolitana de Curitiba. In: MENDONÇA, F. A. Cidade, desenvolvimento e meio ambiente: a abordagem interdisciplinar de problemáticas socioambientais urbanas de Curitiba e Região Metropolitana. Curitiba: Editora da UFPR, 2004a, pgs.11-30.

14 . . S.A.U. - Sistema Ambiental Urbano: Uma abordagem dos problemas socioambientais da cidade. In: MENDONÇA, F. (Org.). Impactos socioambientais urbanos. Curitiba: UFPR, 2004b (pgs.185-208).

15. . Riscos, vulnerabilidade e abordagem socioambiental urbana: uma reflexão a partir da RMC e de Curitiba. Desenvolvimento e Meio Ambiente, n. 10, p.139-148, jul./dez. 2004c.

16. Riscos, vulnerabilidades e resiliência socioambientais urbanas: Inovações na análise geográfica. Revista da ANPEGE, v. 7, pgs 99-109, 2011.

17. . Resiliência Urbana: Concepções e desafios em face de mudanças climáticas globais. In: FURTADO, F.; PRIORI JUNIOR, L., ALCANTARA, E. (Orgs). Mudanças climáticas e resiliência de cidades. Recife: Pikimagem, 2015 (pgs. 45-60).

18. MENDONÇA, Francisco; DESCHAMPS, Marley; LIMA, Myriam D.V.de. A cidade e as mudanças globais: (intensificação?) - Riscos e Vulnerabilidades Socioambientais na RMC - Região Metropolitana de Curitiba/ PR. In: OJIMA, Ricardo; MARANDOLA JR, Eduardo. Mudanças Climáticas e Cidades: novos e antigos debates na busca da sustentabilidade urbana e social. São Paulo: Blucher - Coleção População e Sustentabilidade, 2013. pgs.129-162.

19. MENDONÇA, Francisco; BUFFON, Elaiz A. M.; GOUDARD, Gabriela. l'adaptation urbaine au changement climatique global: les inondations à Curitiba et Pinhais (Brésil) In: XXVIIIe Coloque de l'Associon Internationale de Climatologie. Liège (Sart-Tilman)/Belgique, 2015, pgs. 200-205.

20. OLIVEIRA, Marcelo. A. T; HERRMANN, Maria Lúcia P. Ocupação do Solo e Riscos Ambientais na Área Conurbada de Florianópolis. In: GUERRA, A. J. T. e CUNHA, S. B. Impactos Ambientais Urbanos no Brasil - 4a ed. Rio de Janeiro: Bertrand Brasil, 2006. pgs.147-188.

21. PELLING, Mark. The vulnerability of cities: natural disaster and social resilience. London: Earthscan, 2003. 
22. SAMPAIO, Tony V. M. Diretrizes e procedimentos metodológicos para a cartografia de síntese com atributos quantitativos via álgebra de mapas e análise multicritério. Boletim de Geografia, Maringá, v. 30, n. 1, pgs. 121-131, 2012.

23. SANTOS, Milton. A urbanização brasileira. São Paulo: Hucitec, 1993.

24. SILVEIRA, Wivian N.; KOBIYAMA, Massato; GOERL, Roberto F.; BRANDENBURG, B. História das inundações em Joinville (1851-2008). Curitiba, PR: Organic Trading, 2009. 153 p.

25. SUDERHSA - Superintendência Desenvolvimento de Recursos Híbridos e Saneamento Ambiental. Plano Diretor de Drenagem para a Bacia do Rio Iguaçu na Região Metropolitana de Curitiba. Relatório final - volume 5: plano de ação para situações de emergência. Curitiba, dez/2002, pgs. $1-66$.

26. TUCCI, Carlos E. M. Inundações e drenagem urbana. In: TUCCI, C. E. M. \& BERTONI, C. Inundações urbanas na América do Sul. Porto Alegre, RS: Associação Brasileira de Recursos Hídricos, 2003.

27. ZANELLA, Maria Eliza. Inundações urbanas em Curitiba/PR: impactos, riscos e vulnerabilidade socioambiental no bairro Cajuru. 256 f. Tese (Doutorado em Geografia) Setor Ciências da Terra, Universidade Federal do Paraná, Curitiba, 2006.

Artigo recebido em 11 de abril de 2015.

Artigo aceito em 11 de abril de 2016. 